\title{
FAKTOR-FAKTOR YANG BERHUBUNGAN DENGAN KEJADIAN DISMENOREA PADA MAHASISWI AKADEMI KEBIDANAN PANCA BHAKTI PONTIANAK TAHUN 2019
}

\section{Telly Katharina ${ }^{1}$, Denny Pebrianti ${ }^{2}$}

\author{
Akademi Kebidanan Panca Bhakti Pontianak \\ Email korespondensi: akbidpbpontianak@gmail.com
}

\begin{abstract}
Abstrak
Nyeri menstruasi umum dirasakan oleh perempuan pada hari-hari pertama menstruasi. Gejala-gejala nyeri menstruasi umumnya berupa rasa sakit yang datang secara tidak teratur dan tajam, serta kram dibagian bawah perut yang biasanya menyebar ke bagian belakang, menjalar ke kaki, pangkal paha, dan vulva (bagian luar alat kelamin perempuan). Tujuan dari penelitian ini adalah untuk mengetahui faktor-faktor yang berhubungan dengan kejadian dismenorea pada mahasiswi Akademi Kebidana Panca Bhakti Pontianak. Metode Penelitian ini menggunakan metode analitik dengan pendekatan cross sectional. Populasi pada penelitian ini adalah Mahasiswi Tingkat I dan II di Akademi Kebidanan Panca Bhakti Pontianak yang mengalami disminorea berjumlah 104 orang. Sampel menggunakan teknik Taro Yamane/Solvin berjumlah yang berjumlah 51 orang. Hasil penelitian di dapatkan mahasiswi yang mengalami dismenorea primer sebanyak 27 orang $(52,9 \%)$, sebanyak 29 orang $(56,9 \%)$ mempunyai riwayat keturunan dismenorea dalam keluarga, sebanyak 26 orang $(51,0 \%)$ berusia $7-12$ tahun mengalami menarche, sebanyak 45 orang $(88,2 \%)$ mengalami masa $<7$ hari lamanya menstruasi, sebanyak 31 orang $(60,8 \%)$ mempunyai Indeks Masa Tubuh normal $(18,5-25,0)$. Ada hubungan antara riwayat keluarga dengan kejadian dismenorea $(\mathrm{P}=0.000(\mathrm{P} \leq$ alpha 0.05$)$, tidak ada hubungan antara usia menarche dengan kejadian dismenorea ( $\mathrm{P}$ $=1.164 \mathrm{P}>$ alpha 0.05$)$, tidak ada hubungan antara lama menstruasi dengan kejadian dismenorea $(\mathrm{P}=0.347(\mathrm{P}>$ alpha 0.05), ada hubungan antara IMT dengan kejadian dismenorea $(\mathrm{P}=0.003(\mathrm{P} \leq$ alpha 0.05). Hasil analisis multivariat diketahui bahwa variabel yang paling dominan berhubungan dengan kejadian dismenorea adalah variabel keturunan dalam keluarga dengan nilai odds ratio yaitu $\mathrm{OR}=1,127$, artinya riwayat keturunan dalam keluarga berpeluang untuk terjadinya dismenorea 1,127 kali, setelah dikontrol oleh variabel lamanya menstruasi, usia menarche dan Indeks Masa Tubuh (IMT).
\end{abstract}

Kata Kunci: faktor, dismenorea, mahasiswi

\section{Pendahuluan}

Nyeri menstruasi umum dirasakan oleh perempuan pada hari-hari pertama menstruasi. Gejala-gejala nyeri menstruasi umumnya berupa rasa sakit yang datang secara tidak teratur dan tajam, serta kram dibagian bawah perut yang biasanya menyebar ke bagian belakang, menjalar ke kaki, pangkal paha, dan vulva (bagian luar alat kelamin perempuan) (Laila, 2011).

Sebagian dokter beranggapan bahwa nyeri menstruasi terjadi karena prostaglandin, yaitu zat yang menyebabkan otot rahim

\footnotetext{
${ }^{1}$ Dosen Akademi Kebidanan Panca Bhakti Pontianak

${ }^{2}$ Dosen Akademi Kebidanan Panca Bhakti Pontianak
}

berkontraksi. Pada sebagian perempuan, nyeri menstruasi yang dirasakan dapat berupa nyeri yang samar, tetapi bagi sebagian yang lain dapat terasa kuat bahkan bisa membuat aktivitas terganggu (Laila, 2011).

Nyeri haid sendiri beragam. Mungkin sekedar melilit atau bisa lebih dari itu. Nyerinya luar biasa sampai berguling-guling dan berkeringat dingin. Nyerinya menjalar sampai kepaha dan bisa sampai kepaha dan bisa sampai kepinggang. Tentu saja mereka yang suka nyeri haid bukan berarti tergolong wanita tidak subur. 
Nyeri haid berarti hanya terganggu oleh rasa tidak nyaman saja. Mungkin tak cukup obat warung saja. Resep dokter bisa menolong (Nadesul, 2008).

Nyeri pada saat menstruasi dari beberapa derajat mempengaruhi lebih banyak dari suatu perkiraan 50\% dari wanita-wanita, dan diantara ini, sampai dengan $15 \%$ akan menggambarkan nyeri menstruasi yang berat. Survey - survey dari gadis remaja menunjukkan bahwa lebih dari $90 \%$ gadis-gadis melaporkan mempunyai nyeri pada saat menstruasi (Sukarni, 2013).

Ada dua tipe dari disminorea, Primary (Primer) dan secondary (sekunder). Disebut disminorea primer jika tidak ditemukan penyebab yang mendasarinya dan disminorea sekunder jika penyebabnya adalah kelainan kandungan. Disminorea primer sering terjadi, kemungkinan lebih dari $50 \%$ wanita mengalaminya dan $15 \%$ diantaranya mengalami nyeri pada saat menstruasi yang hebat (Sukarni, dkk, 2013).

Lebih dari 50 persen wanita yang sedang mengalami menstruasi mengalami nyeri setiap bulannya,menurut American Congress of Obstetricians and Gynecologists. Meskipun kebanyakan nyeri haid dapat hilang dengan sendirinya, jika berlangsung sepanjang hari, tentu mengganggu produktivitas harian (Oktavia, 2017).

Nyeri yang dirasakan semakin hebat ketika bekuan atau potongan jaringan dari lapisan rahim melewati serviks, terutama jika saluran serviksnya sempit. Faktor lain yang bisa memperburuk disminorea adalah rahim yang menghadap ke belakang, kurangnya berolah raga, stress psikis dan stress sosial (Sukarni, dkk, 2013).

Banyak teori telah dikemukakan untuk menerangkan penyebab disminore, tetapi psikologisnya belum jelas dimengerti. Rupanya beberapa faktor memegang peranan sebagai penyebab disminore yaitu faktor kejiwaan, faktor konstitusi, faktor obtruksi kanalis servikalis, faktor endokrin dan faktor alergi (Sukarni, dkk, 2013).

Oleh karena hampir semua wanita mengalami rasa tidak enak di perut bagian bawah sebelum dan selama haid dan seringkali rasa mual, maka istilah dismenorea hanya dipakai jika nyeri haid sedemikian hebatnya, sehingga memaksa penderita untuk istirahat dan meninggalkan pekerjaan atau cara hidupnya sehari-hari, untuk beberapa jam atau beberapa hari (Sukarni, dkk, 2013).

Salah satu faktor yang turut mempengaruhi terjadinya gangguan menstruasi yang berupa disminorea primer berhubungan erat dengan adanya gangguan hormon, terutama yang berhubungan dengan hormon seksual wanita yaitu progesteron, esterogen, $L H$ dan FSH. Hormon-hormon seksual tersebut sangat berfungsi pada sistem reproduksi wanita. Namun pada beberapa kejadian terjadi peningkatan salah satu saja yang menunjukkan ketidakseimbangan sintesis hormon dalam tubuh dan hal ini akan mempengaruhi perangsangan terjadinya gangguan menstruasi. Adanya gangguan dari kerja sistem hormonal terkait dengan status gizi (Irianto, 2014).

Perempuan dengan disminorea primer didapatkan kadar prostaglandin lebih tinggi 
dibandingkan perempuan tanpa disminorea. Peningkatan kadar prostaglandin tertinggi saat haid terjadi pada 48 jam pertama. Hal ini sejalan dengan awal muncul dan besarnya intensitas keluhan nyeri haid (Prawihardjo, 2011).

Hasil penelitian Tia Marta Pundati dkk, menunjukkan bahwa sampel berjumlah 85 orang dari jumlah populasi 1.563 orang, dengan menggunakan teknik proporsional stratified random sampling didapatkan hasil 67,1 \% responden mengalami disminorea, 57,6\% responden berusia diatas 12 tahun, $71,8 \%$ responden tidak memiliki riwayat keluarga, $55,3 \%$ memiliki riwayat > 7 hari, 50,6\% mengalami stress dan $51,7 \%$ memiliki aktivitas fisik rutin. Dengan hasil uji chi square menunjukkan ada hubungan yang signifikan antara menstruasi dan dismenorea dengan $\mathrm{p}=$ $0,03(\mathrm{p}<0,05)$; ada hubungan yang signifikan antara stress dengan kejadian dismenorea dengan $p=0,023(p>0,05)$. Faktor yang tidak ada hubungan antara kejadian dismenorea adalah usia menarche, riwayat keluarga dan kebiasaan olahraga.

Penelitian dari Eka Yuli Handayani, 2014 memperoleh hasil univariat yaitu umur responden rata-rata 16,48 tahun, responden tidak berolahraga secara teratur berjumlah 33 orang $(82,5 \%)$, mempunyai riwayat keluarga 38 orang (95\%), menarche pada usia 12-14 tahun 34 orang (85\%). Hasil bivariate pada umur $\mathrm{p}=0,051$ tidak memiliki hubungan terhadap dismenorea, olahraga memiliki hubungan dengan nilai $\mathrm{p}=0,028$, riwayat keluarga memiliki hubungan dengan nilai $\mathrm{p}=$ 0,0005, usia menarce tidak memiliki hubungan $p=0,381$. Diperoleh variabel yang besar pengaruhnya adalah olahraga teratur dengan $\mathrm{OR}=3,484$ dan disusul dengan riwayat keluarga. Sedangkan umur dan menarche tidak memiliki hubungan yang signifikan terhadap dismenorea.

Tabel 1. Jumlah Mahasiswi yang Mengalami Disminorea dan Tidak Dismenorea Di Akademi Kebidanan Panca Bhakti Pontianak Tahun 2019

\begin{tabular}{ccccc}
\hline Kategori Disminora / & \multicolumn{2}{c}{ Tingkat I } & \multicolumn{2}{c}{ Tingkat II } \\
\cline { 2 - 5 } Tidak Disminorea & Frekuensi & Persentase (\%) & Frekuensi & Persentase (\%) \\
\hline Disminorea & 39 & $57,36 \%$ & 65 & $60,75 \%$ \\
Tidak Disminorea & 29 & $42,64 \%$ & 42 & $39,25 \%$ \\
Jumlah & 68 & $100 \%$ & 107 & $100 \%$ \\
\hline
\end{tabular}

Peneliti melakukan studi pendahuluan pada mahasiswi Akademi Kebidanan Panca Bhakti Pontianak. Berdasarkan tabel 1.1 diketahui bahwa jumlah mahasiswa Akademi Kebidanan Panca Bhakti Pontianak pada tingkat I berjumlah 68 orang dan tingkat II berjumlah 107 orang. Tingkat I yang mengalami disminorea berjumlah 39 orang $(57,36 \%)$ dan yang tidak disminorea berjumlah 29 orang (42,64\%) sedangkan Tingkat II berjumlah 65 orang $(60,75 \%)$ dan yang tidak disminorea berjumlah 42 orang $(39,25 \%)$.

Berdasarkan studi pendahuluan yang dilakukan pada 20 mahasiwi Akademi Kebidanan Panca Bhakti Pontianak tingkat I dan tingkat II dengan wawancara sederhana 
pada tanggal 28 Februari 2019, terdapat sebanyak 11 mahasiswa (55\%) pernah mengalami disminorea dalam 6 bulan terakhir.

\section{Metode Penelitian}

Penelitian ini menggunakan metode analitik dengan pendekatan cross sectional. Lokasi penelitian dilakukan di Kampus Akademi Kebidanan Panca Bhakti Pontianak
Kalimantan Barat. Dalam penelitian ini, jumlah populasi yang diteliti adalah Mahasiswi Tingkat I dan II di Akademi Kebidanan Panca Bhakti Pontianak yang mengalami disminorea berjumlah 104 orang. Dalam Penelitian ini peneliti menggambil sampel menggunakan teknik Taro Yamane/Solvin sampel dalam penelitian ini berjumlah 51 orang.

\section{Hasil dan Pembahasan}

Tabel 2. Distribusi Frekuensi Pada Mahasiswi Akademi Kebidanan Panca Bhakti Tahun 2019

\begin{tabular}{lcc}
\hline \multicolumn{1}{c}{ Karakteristik Responden } & F & $\%$ \\
\hline Kejadian Dismenorea & & \\
$\quad$ Disminorea Sekunder & 24 & 47.1 \\
$\quad$ Disminorea Primer & 27 & 52.9 \\
Riwayat Keluarga & & \\
$\quad$ Ada Riwayat & 29 & 56,9 \\
$\quad$ Tidak Ada Riwayat & 22 & 43,1 \\
Usia Menarche & & \\
$\quad$ 7-12 tahun & 26 & 51,0 \\
$\quad>12$ tahun & 25 & 49,0 \\
Lama Menstruasi & & \\
$\quad>7$ hari & 6 & 11,8 \\
$\quad$ >7 hari & 45 & 88,2 \\
IMT $\quad$ & 39,2 \\
$\quad$ Tidak Normal & 20 & 60,8 \\
$\quad$ Normal & 31 & \\
\hline
\end{tabular}

Berdasarkan tabel diatas diketahui bahwa dari 51 responden mahasiswi yang mengalami dismenorea primer sebanyak 27 orang $(52,9 \%)$. Mahasiswi yang mempunyai riwayat pada keluarga yang mengalami dismenorea sebanyak 29 orang $(56,9 \%)$, mahasiswi yang usia menarchenya 7 - 12 tahun sebanyak 26 orang $(51,0 \%)$, mahasiswi yang mengalami lamanya menstruasi $<7$ hari sebanyak 45 orang $(88,2 \%)$ dan mahasiswi yang Indeks Masa Tubuh normal sebanyak 31 orang $(60,8 \%)$.

Tabel 3. Analisis Bivariat

\begin{tabular}{|c|c|c|c|c|c|c|c|c|}
\hline \multirow{3}{*}{ Karakteristik } & \multicolumn{4}{|c|}{ Kejadian dismenorea } & \multirow{2}{*}{\multicolumn{2}{|c|}{ Total }} & \multirow{3}{*}{$P$ value } & \multirow{3}{*}{ OR } \\
\hline & \multicolumn{2}{|c|}{$\begin{array}{c}\text { Dismenorea } \\
\text { sekunder }\end{array}$} & \multicolumn{2}{|c|}{$\begin{array}{c}\text { Dismenorea } \\
\text { sekunder }\end{array}$} & & & & \\
\hline & $\mathrm{n}$ & $\%$ & $\mathrm{n}$ & $\%$ & $\mathrm{n}$ & $\%$ & & \\
\hline \multicolumn{9}{|l|}{ Riwayat Keluarga } \\
\hline Ada & 14 & 48,3 & 15 & 51,7 & 29 & 100 & \multirow{2}{*}{0,000} & \multirow{2}{*}{$\begin{array}{c}1,120 \\
(0,3669-3,403)\end{array}$} \\
\hline Tidak ada & 10 & 45,5 & 12 & 54,5 & 22 & 100 & & \\
\hline
\end{tabular}




\begin{tabular}{lcccccccc}
\hline \hline Usia Menarche & & & & & & & & \\
$\quad 7-12$ tahun & 15 & 57,7 & 11 & 42,3 & 26 & 100 & 1,164 & 2,424 \\
$\quad>12$ tahun & 9 & 36 & 16 & 64 & 25 & 100 & & $(0,785-7,489)$ \\
$\quad \begin{array}{l}\text { Lama Menstruasi } \\
\quad>\text { hari }\end{array}$ & 4 & 66,7 & 2 & 33,7 & 6 & 100 & & \\
$\quad<7$ hari & 20 & 44,4 & 25 & 55,6 & 45 & 100 & 0,347 & $(0,415-15,069)$ \\
$\quad$ IMT & & & & & & & & \\
$\quad$ Tidak Normal & 10 & 50 & 10 & 50 & 20 & 100 & & 0,009 \\
$\quad$ Normal & 14 & 45,2 & 17 & 54,8 & 31 & 100 & & $(0,394-3,745)$ \\
\hline
\end{tabular}

Berdasarkan tabel diatas diketahui hasil analisis hubungan antara riwayat keluarga dengan kejadian desmenorea diperoleh bahwa nilai $\mathrm{P}=0.000$ ( $\mathrm{P} \leq$ alpha 0.05$)$, maka dapat disimpulkan ada perbedaan yang signifikan pada kejadian dismenorea antara responden yang memiliki riwayat keluarga dismenorea dengan responden yang tidak memiliki riwayat keluarga dismenorea (ada hubungan antara riwayat keluarga dengan kejadian dismenorea).

Hasil analisis hubungan antara usia menarche dengan kejadian dismenorea diperoleh bahwa nilai $\mathrm{P}=1.164(\mathrm{P}>$ alpha 0.05), maka dapat disimpulkan tidak ada perbedaan yang signifikan pada kejadian dismenorea antara responden yang mengalami usia menarche 7-12 tahun dengan responden yang mengalami usia menarche $>12$ tahun (tidak ada hubungan antara usia menarche dengan kejadian dismenorea).

Hasil analisis hubungan antara lama mentruasi dengan kejadian dismenorea diperoleh bahwa nilai $\mathrm{P}=0.347(\mathrm{P}>$ alpha 0.05), maka dapat disimpulkan tidak ada perbedaan yang signifikan pada kejadian dismenorea antara responden yang lama mentruasinya $>7$ hari dengan responden yang lama menstruasinya $<7$ hari (tidak ada hubungan antara lama menstruasi dengan kejadian dismenorea).

Berdasarkan analisis hubungan antara IMT dengan kejadian desmenorea diperoleh bahwa diperoleh nilai $\mathrm{P}=0.003(\mathrm{P} \leq$ alpha 0.05), maka dapat disimpulkan ada perbedaan yang signifikan pada kejadian dismenorea antara responden yang memiliki IMT tidak normal dengan responden yang memiliki IMT normal (ada hubungan antara IMT dengan kejadian dismenorea). Dari hasil analisis diperoleh pula nilai $\mathrm{OR}=1.214$, artinya responden yang memiliki IMT tidak normal mempunyai peluang 1.214 kali untuk mengalami kejadian dismenorea dibanding responden yang memiliki IMT normal.

Tabel 4. Analisis Multivariat

\begin{tabular}{llllcr}
\hline \multirow{2}{*}{ Variabel } & \multicolumn{2}{c}{ Beta } & \multicolumn{2}{c}{$\begin{array}{c}\text { Adjusted } \\
\text { Or }\end{array}$} & \multicolumn{2}{c}{ 95 \% Ci } \\
\cline { 5 - 6 } \cline { 4 - 5 } Riwayat keluarga & 0,120 & 1,127 & 0,370 & 3,430 \\
IMT & 0,198 & 0,537 & 0,395 & 1,026 \\
Constant & $-0,054$ & 0,067 & & \\
\hline
\end{tabular}


Berdasarkan tabel diatas dapat dilihat bahwa kekuatan hubungan antara disminorea dengan riwayat keluarga lebih besar $(\mathrm{OR}=1,127)$ dibandingkan hubungan antara disminorea dengan IMT $(\mathrm{OR}=0,537)$. Hasil analisis diketahui bahwa variabel yang paling dominan berhubungan dengan kejadian disminorea adalah variabel keturunan dalam keluarga dengan nilai odds ratio yaitu $\mathrm{OR}=1,127$, artinya riwayat keturunan dalam keluarga berpeluang untuk terjadinya disminorea 1,127 kali, setelah dikontrol oleh variabel lamanya menstruasi, usia menarche dan Indeks Masa Tubuh (IMT).

Dismenorea sebagian besar dialami oleh responden yang yang mempunyai riwayat keluarga atau keturunan dismenorea pula. Hasil penelitian menunjukkan bahwa riwayat keluarga atau keturunan mempunyai pengaruh terhadap kejadian dismenorea. Riwayat keluarga merupakan faktor resiko yang dapat meningkatkan kemungkinan terjadinya dismenorea. Dua dari tiga wanita yang menderita dismenorea mempunyai riwayat dismenorea pada keluarganya. Banyak gadis yang menderita dismenorea dan sebelumnya mereka sudah diperingatkan oleh ibunya bahwa kemungkinan besar akan menderita dismenorea juga seperti ibunya (Coleman, 1991).

Hasil penelitian ini ternyata sesuai dengan teori yang ada yaitu ada pengaruh riwayat keluarga atau keturunan dismenorea terhadap kejadian dismenorea. Dengan kata lain, responden yang mengalami dismenorea sebagian terjadi pada mereka yang mempunyai riwayat keluarga atau keturunan dismenorea pula. Responden yang mempunyai riwayat keluarga atau keturunan dismenorea mempunyai resiko 1, 127 kali untuk terkena dismenorea dibandingkan dengan responden yang tidak memiliki riwayat keluarga atau keturunan dismenorea.

Menurut Widjanarko (2006), riwayat penyakit dalam keluarga dapat mengidentifikasi seseorang dengan resiko lebih tinggi untuk mengalami suatu penyakit yang sering terjadi. Adanya riwayat keluarga dan genetik berkaitan dengan terjadinya dismenorea yang berat (dismenorea primer). Riwayat keluarga mempunyai peran untuk terjadinya dismenorea, maka perlu upaya preventif terhadap dismenorea yang sering terjadi saat wanita mengalami menstruasi terutama bagi wanita yang mempunyai riwayat keluarga positif dismenorea (Rahmawati, 2009).

Menurut Ani Kristianingsih (2014), riwayat keluarga memiliki pengaruh terhadap terjadinya dismenorea. Hal tersebut dikarenakan seseorang yang mempunyai riwayat penyakit keluarga beresiko lebih besar dibandingkan dengan yang tidak mempunyai riwayat. Dalam keluarga banyak faktor yang saling berkaitan terutama faktor genetik, karena dalam kesehatan keluarga mempunyai peran penting terhadap kesehatan anggota keluarganya. 


\section{Kesimpulan}

Hasil analisis diketahui bahwa variabel yang paling dominan berhubungan dengan kejadian dismenorea adalah variabel keturunan dalam keluarga dengan nilai odds ratio yaitu $\mathrm{OR}=$

\section{Daftar Pustaka}

Achinntya, Amanda Sagung. 2017. Hang Tuah Medical Journal. www.journalmedical.hangtuah.ac.id, diakses: 26 Februari 2018, 14.45 WIB

Alodokter. 2016. Pemahaman Seputar Indek Massa Tubuh. http://www.alodokter.com/pemahaman -seputar-indeks-massa-tubuh, diakses: 30 Maret 2018,19.55 WIB

Ani, Kristianingsih, Factor Resiko Dismenorea Primer Pada Siswi Sekolah Menengah Pertama (SMP X) Kecamatan Nater Kabupaten Lampung Selatan, Prodi Kebidanan Stikes Aisyah Pringsewu, Lampung

Anurogo, Dito., Ari Wulandari. 2011. Cara Jitu Mengatasi Nyeri Haid. Penerbit Andi: Yogyakarta

Bobak, I.M., Lowder Milk, D.L. Jensen, M.D (2004). Buku Ajar Keperawatan Maternitas. Edisi 4. Jakarta: EGC

Benson, dkk. 2009. Buku Saku Obstetri dan Ginekologi. Jakarta: EGC

Gumangsari, Ni Made Gita, 2014. Pengaruh Massase Counterpressure Terhadap Penurunan Tingkat Nyeri Haid Pada Remaja Putri Di SMA N 2 Unggaran Kabupaten Semarang

Harmoni, Hesti Pratiwi. 2018. Hubungan Antara IMT dan Aktifitas Fisik dengan Kejadian Disminora di SMA Batik 1 Surakarta.

http://jurnal.fk.unand.ac.id/index.php/j $\mathrm{ka} /$ article/download/640/505, diakses: 26 Februari 2018, 15.00 WIB
1,127 , artinya riwayat keturunan dalam keluarga berpeluang untuk terjadinya dismenorea 1,127 kali, setelah dikontrol oleh variabel lamanya menstruasi, usia menarche dan Indeks Masa Tubuh (IMT).

Hasdianah, dkk. 2014. Gizi, Pemanfaatan Gizi,Diet dan Obesitasi. Yogyakarta: Nuha Medika

Irianto, Koes. 2014. Gizi Seimbang dan Kesehatan Reproduksi. Bandung: Alfabeta

Irianto, Pekik Djoko. 2017. Pedoman Gizi Lengkap: Keluarga dan Olahraga. Yogyakarta: CV. Andi Offset

Laila, Najmi Nur. 2011. Buku Pintar Menstruasi. Jogjakarta: Buku Biru

Marmi, 2013. Gizi dalam Kesehatan Reproduksi. Yogyakarta: Pustaka Pelajar

Maulana, Mirza. 2009. Seluk Beluk Reproduksi dan Kehamilan. Jogjakarta: Gerai Ilmu

More, Judy. 2014. Gizi Bayi, Anak dan Remaja. Yogyakarta: Pustaka Pelajar Offset

Morgan, dkk. 2009. Obstetri dan Ginekologi. Jakarta: EGC

Nadesul, Hendrawan. 2008. Cara Sehat Menjadi Perempuan. Jakarta: PT. Kompas Media Nusantara

Nugroho, dkk, 2014. Masalah Kesehatan Reproduksi Wanita. Yogyakarta: Nuha Medika

Oktavia, Nadia. 2017. 6 Kiat Alami Atasi Nyeri Haid. http://health.liputan6.com/read/290455 4/6-kiat-alami-atasi-nyeri-haid, diakses : 3 Maret 2018, 00:26 WIB

Paath, E.F, 2007. Gizi Dalam Kesehatan Reproduksi. Jakarta: EGC 
Pebrina, M. 2016. Hubungan Status Gizi Dengan Dismenorea, Jurnal Kesehatan Medika Saintika

Pratiwi, H.H, 2017. Hubungan antara IMT dan Aktivitas Fisik dengan Kejadian Dismenorea Di SMA Batik I Surakarta, Universitas Muhammadiyah Surakarta

Prawihardjo, Sarwono. 2010. Ilmu Kandungan. Jakarta: PT. Bina Pustaka Sarwono Prawihardjo

.2011. Ilmu Kandungan Edisi Ketiga. Jakarta: PT. Bina Pustaka Sarwono Prawihardjo

Sarwono, 2007. Psikologi Remaja, Jakarta: Raja Grafindo Persada

Sibagariang, Ellya Eva. 2010. Gizi Dalam kesehatan Reproduksi. Jakarta: CV. Trans Info Media

Sibagariang,dkk. 2010. Kesehatan Reproduksi Wanita. Jakarta: Cv. Trans Info Media

Siswanto, dkk. 2014. Metodelogi Penelitian Kesehatan dan Kedokteran. Yogyakarta : Bursa Ilmu

Sukarni, dkk. 2013. Kehamila, Persalinan dan Nifas. Yogyakarta: Nuha Medika

.2013. Keperawatan Maternitas. Yogyakarta: Nuha Medika

Susila, dkk. 2015. Metodologi Penelitian Cross Sectional. Kalteng Selatan: BOSSSCRIPT

Shopia Frenih. 2013. Faktor-Faktor Yang Berhubungan Dengan Dismenorea Pada Siswi SMK Negeri 10 Medan Tahun 2013

Tia Martha Pundati, Colti Sistiarani, Bambang Hariyadi, Jurusan Kesehatan Masyarakat. Fakultas Ilmu-Ilmu Kesehatan, Universitas Jenderal Sudirman, Faktor-Faktor Yang Berhungna Dengan Kejadian Dismenorea Pada Mahasiswa Semester VIII Di Universitas Jendral Sudirman Purwokerto Tahun 2016
Eka Yuli Handayani Dan Lasma Sri Rahayu, 2014. Faktor-Faktor Yang Berhubungan Ngan Nyeri Menstruasi Pada Remaja Putri Di Beberapa SMA Di Kabupaten Rokan Hulu Tahun 2014

Waryana, 2010. Gizi Reproduksi. Yogyakarta: Pustaka Rihama

Widjanarko, B. 2006. Dismenorea Tinjauan Terapi Pada Dismenorea Primer. Volume 5, No.1. Jakarta: Bagian Ilmu Kebidanan Dan Penyakit Kandungan Fakultas Kedokteran Rumah Sakit Universitas Atmajaya 2012. Dismenorea Tinjauan Terapi Pada Dismenorea Primer. Majalah Kedokteran Damianus, 5

Wiknjosastro, H. 2009. Ilmu Kandungan. Jakarta: Yayasan Bina Pustaka Sarwono 